\title{
Research on Design of Products for the Blind Based on Humanistic Care Concept
}

\author{
Yao Shanliang and Fan Jiajun* \\ School of Art \& Design for Wuhan Institute of Technology \\ Wuhan 430205
}

\begin{abstract}
With the development of society and the improvement of individual self-awareness, the emphasis of product design has been gradually transferred from function to emotions, and it pays more attention to the internal demand of users, integrates the emotion factors of users into products to obtain emotional interaction value. This article starts from three aspects, including the function, form, and using mode of blind products, and then analyzes the design and innovation for blind products, put forward that design shall not only make creative efforts but also increase creativity for life, and also reflect the care for special groups. For special groups such as blind people with more emotional demands, designers should give them more humanistic care during the process of product design.
\end{abstract}

Keywords-Blind people; Humanistic care; Function; form; Using mode

\section{INTRODUCTION}

Humans are the most emotional animal on earth, and emotions play a decisive role in the daily life of humans. The cognition, behaviors and other aspects of humans will be driven by emotional factors, and positive emotions can guide the positive development of humans, but negative emotions will bring bad influence on humans. Social progress and the attentions paid to human rights as well as the humanistic care for the disabled have been taken more and more seriously. Normal people will generate intuition after seeing things, and then generate association and thoughts, and the visual joy is a born instinct, but since visually impaired people lose their visual power, they will have more differences and inconveniences when being compared with normal people. This requests designers to consider the appeal of blind people when conducting product design, give them more humanistic care, reasonably use emotional design concept, and let products exert a positive leading function in the emotions and life of blind people, help the vulnerable group of blind people to integrate into social life better and more independently and freely.

\section{BLIND PEOPLE AND THEIR PSYCHOLOGICAL FEATURES}

Blind people refer to people who suffer from eye disease or accidental injury, with partial or complete barriers in visual organ structure or function, which can cause both-eye or single eye blindness. According to the data investigation, the quantity of blind people in our country occupy the most of the total world population worldwide, and the quantity is about $12,000,000$, which can occupy $18 \%$ of the total quantity of blind people worldwide [1].

Due to physiological defects, blind people mainly relies on ear, nose, hand and other organs to acquire external information through the sense of hearing, smell and touch[2]. Due to the partial loss of one important information acquiring approach-vision, the information acquired by blind people can be scattered and slow, so that their cognitive development speed is slow, with the lack of image thinking, and they cannot cognize objects as a whole, possess boundedness for the cognition of events, and are also hard to seize the essence of things, easily use their own known similar events for inference and then cause the occurrence of errors.

Through the relevant investigation, it can be found out that the emotional characteristics of blind people can be mainly divided into the following two aspects: firstly, the reaction is strong self-esteem, and most blind people don't want to use walking sticks for assistance in exploring the way, or wanting anyone to support them for walking. Secondly, the reaction is the relatively closed and isolated personalities. Since their actions are restricted and cannot see their own behaviors, this will influence the association with normal people, and then they will slowly become the marginalized vulnerable group.

\section{CURRENT STATUS ABOUT THE DESIGN OF BLIND PRODUCTS}

Specific to the vulnerable group of blind people occupying a big proportion, most designers attempt to carry out targeted and evolutionary design in product design as per the special demand of blind people.

The key design point for most articles used for blind people is to meet the life demand of blind people, without relying on the help of others. Currently, the articles used for blind people can be approximately divided into several types as follows in the market: the first type is touch type products; such products 
can be generally combined with braille alphabet, and let blind people understand product functions and transmit information through contact mode, with low technical contents, and lower cost; generally, it is applicable to domestic environment. The other type is hearing type products; the using range is relatively wide, but in public places and noisy environment, this will seriously influence the using experience of blind people. Moreover, there are also comprehensive electronic products; such products relying on various sciences and technologies, rather than the functions of simple sense organs and this can improve the product experience of blind people from all aspects, and is closer to the life demand of blind people

Currently, most article designs specific to blind people, regardless of non-barrier design, touch design or smart home design are based on the difference between blind people and normal people in life, and they mostly emphasize on functionality and convenience, but neglects the physical characteristics and emotional feelings of blind people.

\section{REFORM OF DESIGN CONCEPT FOR BLIND PROFUCTS}

Along with scientific and technical development, science and technology have provided powers for the functionalization of product design, while multi-function design has deep origin with humanistic care. Product effect can only be exerted through the use of people, so "people" should be the focus of attention. The product design for blind people has gotten rid of the initial "form following function", paid more attention to the emotional demand of people, put forward the design slogan of "people-oriented", and energetically advocated humanistic care.

Humanistic care is originated from western humanism tradition, and the core is the affirmation of humanity and the value of people [3]. Humanistic care is one of the basic dimensions for Marxist philosophy, and it includes people's personality liberation, freedom and equality, respect people's rational thinking, and care for people's spiritual life, etc.

There are reseraches indicate that, the demand level of people will change with social development, Table 1 is the data statisics made by $\mathrm{K} \cdot$ Davis as per the conditions in America.

TABLE I. K•DAVIS STATISTICS

\begin{tabular}{|c|c|c|}
\hline $\begin{array}{c}\text { Requested } \\
\text { Varieties }\end{array}$ & Percentage in 1938 & Percentage in 1995 \\
\hline $\begin{array}{c}\text { Physiologic } \\
\text { al demand }\end{array}$ & $35 \%$ & $5 \%$ \\
\hline $\begin{array}{c}\text { Safety } \\
\text { demand }\end{array}$ & $45 \%$ & $15 \%$ \\
\hline $\begin{array}{c}\text { Emotional } \\
\text { demand }\end{array}$ & $10 \%$ & $30 \%$ \\
\hline $\begin{array}{c}\text { Esteem } \\
\text { demand }\end{array}$ & $3 \%$ & $26 \%$ \\
\hline $\begin{array}{c}\text { Self- } \\
\text { realization }\end{array}$ & $3 \%$ & \\
\hline
\end{tabular}

It is not difficult to see from the data of the aforementioned table that: along with social development, technical barriers are no longer the main approaches for product competition, and the improvement of products' emotional and spiritual care for consumers has gradually become the new design direction. The product design should consider more the psychological demand of people, and during the design, it is applicable to adopt design methods for form, color, texture, using mode, etc., express and exert the designers' thoughts and design objective, integrate emotions into product design, stimulate association of consumers, generate resonation and obtain spiritual joy and emotional satisfaction during the process of appreciating and using products [4]. Meanwhile, highlight product styles, realize the emotional communication between products and consumers, reinforce product appetency and meanwhile, satisfy people spiritually, and reflect profound humanistic care [5].

\section{REFLECTION OF HUMANISTIC CARE IN THE DESIGN OF BLIND PRODUCTS UNDER MULTI-DIMENSIONAL PERSPECTIVE}

Bai Juyi wrote in the poem called Locust Tree in the Yard: "emotions fill up life, things evoke thoughts." Emotions are born out of things, and evoked because of it. The design integrating emotions can help blind people face life with a more positive attitude and reflect people's humanistic care for the special group of blind people from all aspects, including product function, product form and product using mode.

\section{A. Humanistic care based on functions}

Product is the carrier of functions, and currently, most multi-functional product design can possess human interest while meeting people's life demand and products are suing interesting or funny or scathing and other types to challenge functionalism, of which humanistic care plays a decisive role. When functional design and the emotional integration run through, it can not only meet the user demand for functions, but also meet the demand of users psychologically and emotionally.

As can be seen in Figure 1, it is a medicine bottle specially designed for blind people. Such medicine bottle not only has the form design that can effectively prevent medicines from toppling over, but can also change the traditional medicine bottle opening mode. The bottle cover and the body are connected in one, you can open it through turning it up, so this can effectively avoid the occurrence of situation when the bottle cover and the body are separated and the blind people lose the bottle cover. There are emotional considerations in color, material and texture. There is a distinct texture on the bottle cover, which can bring different emotions for blind people while touching it; besides, it can also have the function to help the blind people to distinguish the medicine bottles, and in order to ensure absolute safety, it has also added the function of voice broadcasting about the drug using descriptions on the bottle cover. Through integrating various auxiliary functions, and combining form and material emotions, this can perfectly solve the demand of blind people in use. 


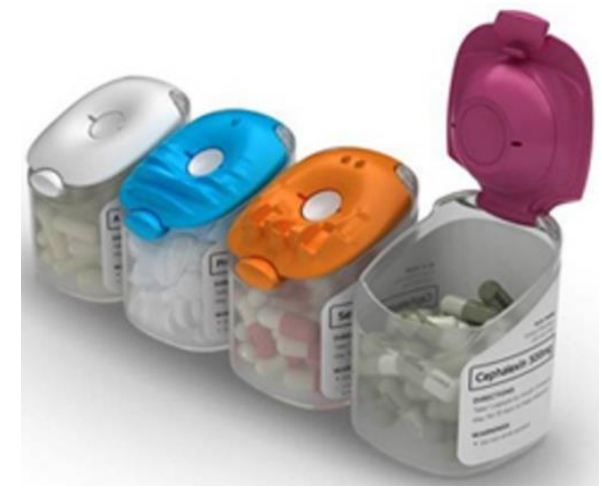

Fig. 1. Medicine Bottle Design for Visually Impaired People

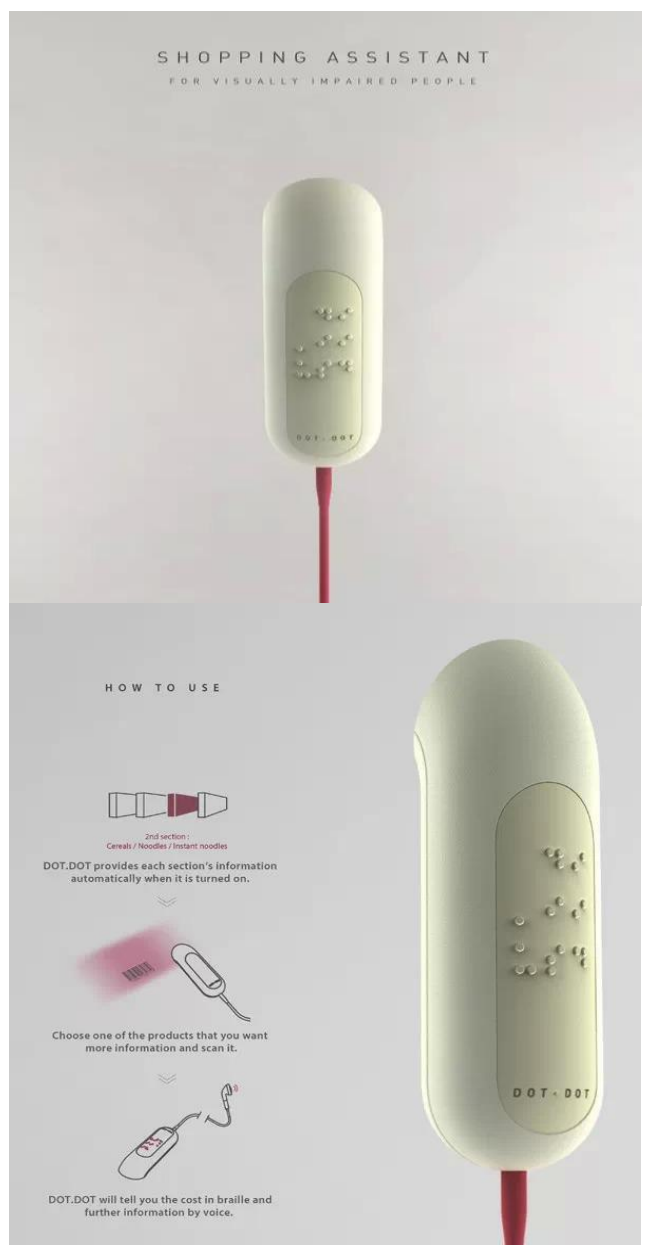

Fig. 2. The smart shopping assistant specially designed for blind people

The Dotdotdot product shown in Figure 2 is a smart shopping assistant creative product designed by designers for visually impaired groups. It has a very strong function, and is like a bar code scanner, which can acquire various information about the supermarket commodities through reading the bar code, of which the product price will be displayed in the touch area in the form of braille alphabet, while others, such as the production date, weight, size, quantity will be broadcasted in phonetic form; besides, it can also provide the supermarket shelf position navigation, and let the visually impaired personnel obtain smooth shopping experience.

\section{B. Humanistic care based on product form}

The product form is the intermediary agent for product function, and without the effect of form, no function can be realized [6]. Meanwhile, form can also have ideographic function, and transmit various kinds of information through form: round can make people feel containment, square can make people feel calm, curve can make people feel mellow and smooth and straight line can make people feel determined and stable. The square, round, curve, straight, visible and invisible forms can bring very different emotional feelings to people

Product color is not only a kind of decoration form, but also an important factor reflecting humanistic care. On one hand, color has emotional effect, and can match with fashionable, or noble, or simple emotional characteristics; meanwhile, color can also possess strong association and symbolism: red can make you feel warm, and it indicates revolution and life; blue represents profoundness and serenity, and white symbolizes purity. Different colors can bring different visual feelings and emotional feelings to people.

The reasonable application of materials can also exert a big assistance effect in the humanistic care for product design. The reasonability of materials can exert the function of adjusting and changing people's spirits and psychology: for instance steel cold curing has the scent of industry, science and technology; timbers, bamboos and other natural materials can show natural, simple and unsophisticated human feelings, etc. [7]. The performance characteristics of material texture and the expressed meanings will directly influence the final visual appearance and touch feeling of products. All of these are the human feelings contained in product design.

In the current society, social life pressure, work pressure and spiritual pressure are everywhere; due to the physiological specialty of blind people, they can internally feel more anxiety and aloneness, with unstable emotions. Therefore, the products used for blind people should be more approachable, to let them feel comfortable and convenient, while obtaining pressure relax. As shown in Figure 4, it is a MP3 for blind people, and the humanistic care of designers for blind people can be fully reflected in the form design of the product. Such small MP3 can be mastered with one hand, and can facilitate the blind people fully recognize the product. The overall form is round, and the form can make people feel its containment; the product surface is changing softly, the prominent details of the key are exquisite and smooth, with soft and comfortable touch. These forms and details can make people feel intimacy. Such design has carefully considered the physiological and psychological demands of blind people from product model, materials and other aspects. 


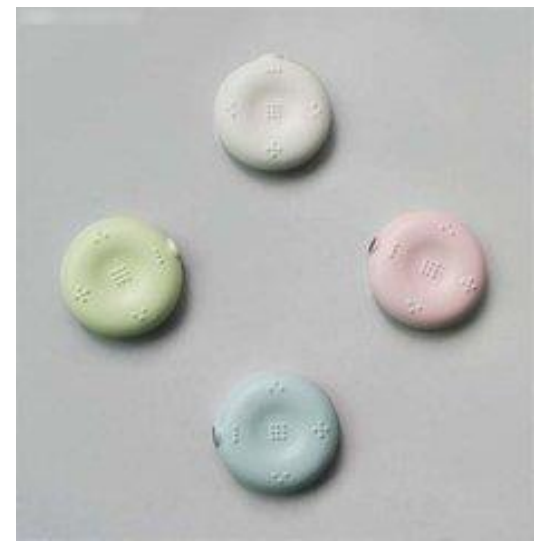

Fig. 3. MP3 Design for Blind People

\section{Humanistic care based on using mode}

In the product using process, except for the comfort level, the product using effect is more important. After all, the improvement of using efficiency is the reasonability of product using mode, which can more efficiently solve the problems in life, and bring comfort and joy to people in the using process.

Blind people mostly lack in interpersonal communication capacity and opportunities, with relatively few emotional experience, with the coexistence of positive emotions and passive emotions. When using products, through the interaction with products, the user can generate joy and satisfaction. As can be seen in Figure 5, it is a mug designed for blind people. This cup is installed with water level inspection device, and along with the change of water level, this cup can make different sounds to remind blind people of paying attention to the water level conditions of the cup, so as to avoid blind people from overflowing water because of their incapacity of recognizing the water level. This cup is added with one water level inspection function, which can make sound with the change of water level, and while solving the life troubles of blind people, in the using process, it can establish interaction between products and users through voice, and let users generate pleasant feelings while using the product, and exert a positive effect on the emotions and psychology of blind people.

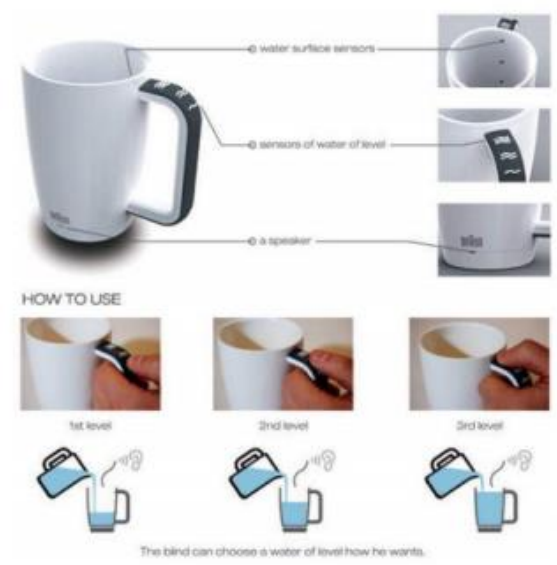

Fig. 4. Mug Design for Blind People
Science and technology are no longer cold and remote, it can not only change people's living mode, but also bring warm and care to people. Figure 6 is a 2C3D camera, which is a camera specially designed by Oren Geva, a designer from Israel for visually impaired people, and it has won 2018 Asian Design Award. In the design, the designer has fully considered the user demand of blind people, and the display screen of such camera is different from common cameras, for it is constituted by several small columns, and each column corresponds to one pixel of certain standard. During its product design, it carries one depth-sensing camera, which can convert visual data to touch dat. In simple terms, the originally plane face can present three-dimensional form through this camera, i.e., 3D. This can make blind people feel the photo contents through touch.

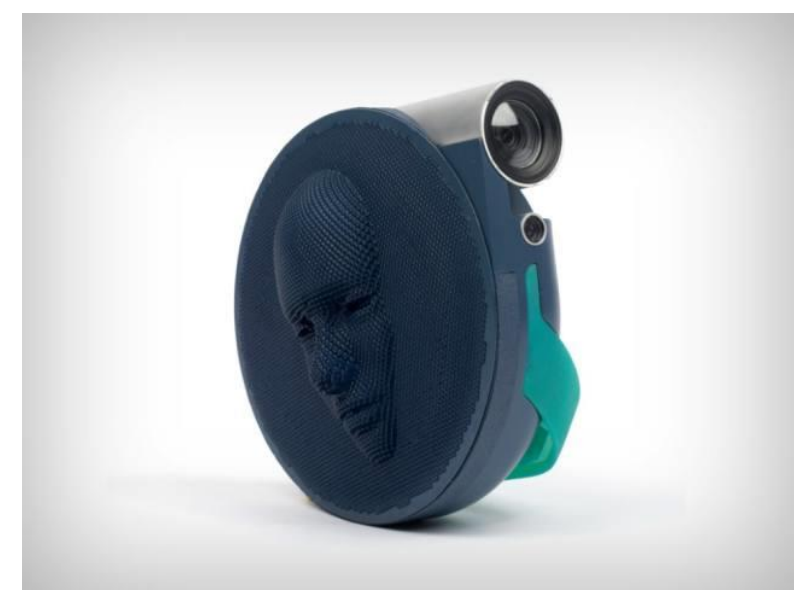

Fig. 5. 2C3D Camera for Blind People

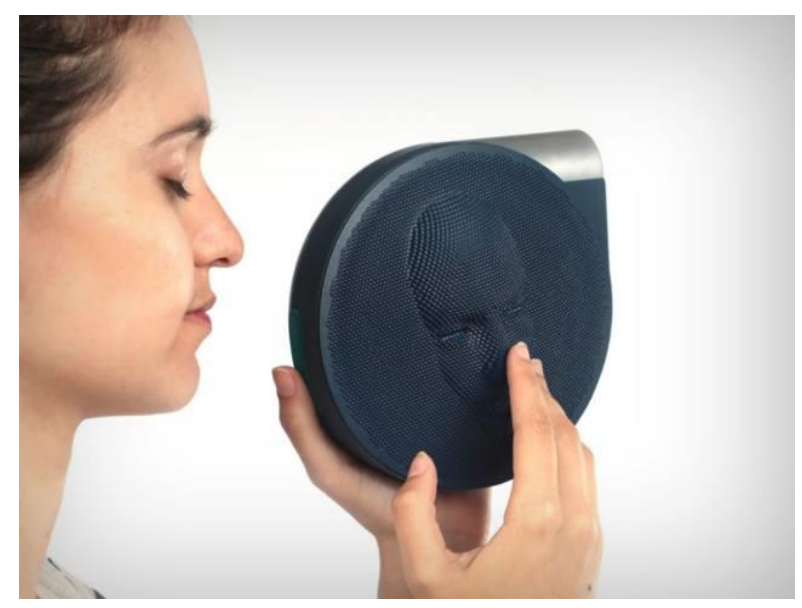

Fig. 6. Camera for Blind People in Use

As can be seen from the aforementioned cases, through analyzing user demand, it is applicable to master the changing rules of their emotions and feelings, and then start from emotions in design purposely and consciously, this can not only meet the material demand of users, but also meet the spiritual demand of users, and then in the design, add the emotional care for consumers, make the products not only an article of daily use, but also possess unique cultural connotation and humanistic care. 


\section{CONCLUSION}

The market effect of products is started from design, and designers are the master of products. During the diversified era of products, emotions are urgently called, and people are seeking for humanistic care. Designers should reasonably extend design touch to the inner heart of people by virtue of the energy of modernized civilization reasonably, and then mark the product with human's spiritual awareness. The design value shouldn't be the pursuit of commercial interests only, when it comes to the humanistic care, social problems, reality solutions, environment protection measures and other abstract problems, design thoughts can play a strong effect, and small designs can also have big idea, and generate big influence, and this is the essence for changing life with design, and changing the world with design!

\section{REFERENCES}

[1] Lai Jingyu and Wang Ronghui. Research about the Intelligence of Walking Stick for Blind People $[\mathrm{J}]$ Heilongjiang Science and Technology Information, 2016 (32)

[2] Lu Chunfu, and Zong Xianxin. Research on the Design Method of Touch Graphic Display of Blind People [J] Design, 2017 (07)

[3] Li Gang. New Exploration about the Research of Humanistic Care [J] Journal of Jiangxi Administration Institute. 2011 (02)

[4] Liu Jie. Research about the Product Joyful Experience Based on Conscious Behaviors

[5] Ren Juanli. Emotional Design in Product Design [J] Guide to Business, 2009 (10)

[6] Zhang Awei. Research and Application of Comprehensive Design Methods for Products Oriented to the Market

[7] Li Zhenhua and Liu Hongxiang. Art Designer Complete Manual [M] Tsinghua University Press, 2006.5. 